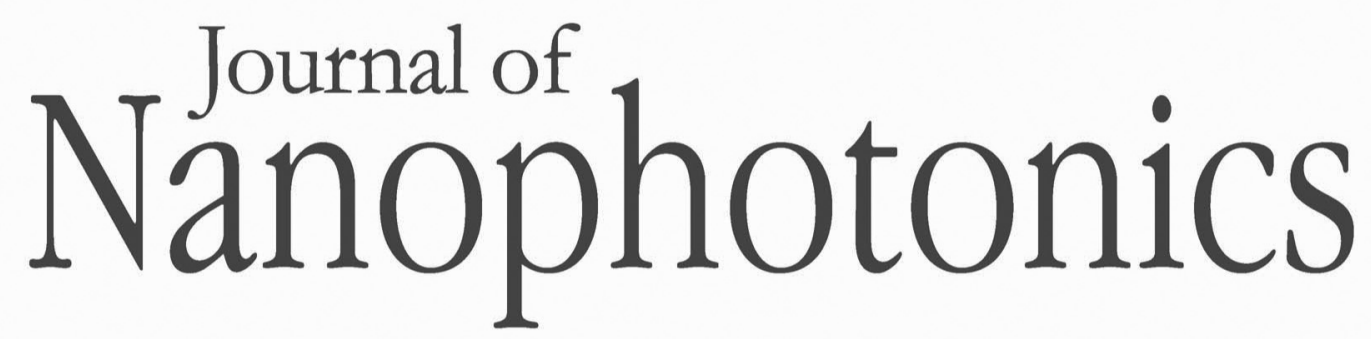

SPIEDigitalLibrary.org/jnp

\title{
Properties and applications of protein- stabilized fluorescent gold nanoclusters: short review
}

Daniel M. Chevrier

Amares Chatt

Peng Zhang

\section{O SPIE}




\title{
Properties and applications of protein-stabilized fluorescent gold nanoclusters: short review
}

\author{
Daniel M. Chevrier, Amares Chatt, and Peng Zhang \\ Dalhousie University, Department of Chemistry, 6274 Coburg Road, P.O. Box 15000, \\ Halifax, Nova Scotia B3H 4R2, Canada \\ peng.zhang@dal.ca
}

\begin{abstract}
Research is turning toward nanotechnology for solutions to current limitations in biomedical imaging and analytical detection applications. New to fluorescent nanomaterials that could help advance such applications are protein-stabilized gold nanoclusters. They are potential candidates for imaging agents and sensitive fluorescence sensors because of their biocompatibility and intense photoluminescence. This review discusses the strategy for synthesizing fluorescent protein-gold nanoclusters and the characterization methods employed to study these systems. Optical properties and relevant light-emitting applications are reported to present the versatility of protein-gold nanoclusters. These new bio-nano hybrids are an exciting new system that remains to be explored in many aspects, especially regarding the determination of gold nanocluster local structure and the enhancement of quantum yields. Understanding how to finely tune the optical properties will be pivotal for improving fluorescence imaging and other nanocluster applications. There is a promising future for fluorescent protein-gold nanoclusters as long as research continues to uncover fundamental structure-property relationships. () 2012 Society of Photo-Optical Instrumentation Engineers (SPIE). [DOI: 10.1117/1.JNP.6 $.064504]$
\end{abstract}

Keywords: fluorescence; medical imaging; particles; sensors.

Paper 12017V received Feb. 20, 2012; revised manuscript received Apr. 25, 2012; accepted for publication May 23, 2012; published online Jul. 19, 2012.

\section{Introduction}

Gold nanoclusters are attracting a wealth of attention in many areas of nanotechnology. These sub-nanometer particles demonstrate molecular-like electronic transitions between HOMOLUMO energy levels, due to their finite cluster size. ${ }^{1,2}$ As a result, energy transitions can be rationalized according to the jellium model $\left(\mathrm{E}_{\text {fermi }} / \mathrm{N}^{1 / 3}\right){ }^{2,3}$ Due to this unique electronic nature of gold nanoclusters, photoluminescent properties are prominent in these nanomaterials, ${ }^{2,4-9}$ generating new opportunities for optical applications.

Gold nanoparticle (Au NP) synthesis is a well-explored field in nanotechnology, ${ }^{10-12}$ reaching across many areas such as chemistry, physics, and biology. However, gold nanocluster (Au NC) synthesis is a relatively new field still in development. The isolation and purification of Au NCs has been a recent scientific achievement, leading to many thorough investigations of both its structure and its implications for nanotechnology. ${ }^{13-15}$ The crystal structures of $\mathrm{Au}_{25}$ and $\mathrm{Au}_{102}{ }^{16,17} \mathrm{NCs}$ have motivated researchers to analyze their novel structures with a variety of experimental methods. Au NCs are already being recognized as potential catalytic agents. ${ }^{18-20}$ Computational and theoretical studies have also played a big part in probing the electronic structure. ${ }^{1,14,21}$ Some of the unique electronic effects of Au NCs can be attributed to a surface staple-like bonding structure between the organic capping ligand and surface gold atoms (see Fig. 1). ${ }^{22-24}$ This is just one feature rendering $\mathrm{Au} \mathrm{NCs}$ to be an exciting nanomaterial for future research.

The effect of the capping/stabilizing ligand has been demonstrated to have a profound effect on the photoluminescence of Au NCs, ${ }^{6,25,26}$ which in turn, influences possible optical applications. An interesting example of modifying the capping material is utilizing proteins and other biomolecules to reduce and arrange gold atoms into stable Au NCs. Many proteins contain active

0091-3286/2012/\$25.00 ㄷ 2012 SPIE 


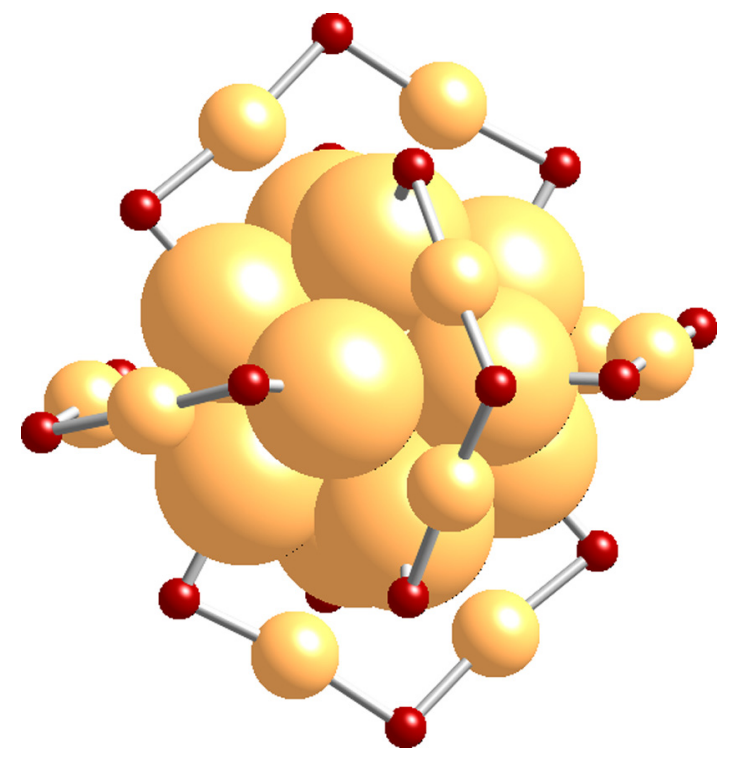

Fig. $1 \mathrm{~A}$ model of the $\mathrm{Au}_{25} \mathrm{NC}$ with surface staple motif "S-Au-S-Au-S". Organic capping ligands are omitted for clarity of the $\mathrm{Au}_{25} \mathrm{NC}$ structure.

sites for metal ion accumulation and reduction where Au NCs can form and be stabilized. Depending on the protein and reaction conditions, Au NCs can be formed with decent fluorescence intensity. It is not until recent years that we have witnessed a dramatic increase in publications investigating fluorescent protein-Au NCs. ${ }^{27}$ Researchers are continually exploring interactions inside these hybrid systems of proteins and metallic particles, establishing new ground for nanomaterials. ${ }^{28,29}$

The intense photoluminescence observed from these protein-stabilized Au NCs has been reported in a number of studies ${ }^{27}$ and is promising for replacing less biocompatible quantum dots used for imaging and targeting applications. ${ }^{30}$ New studies strive to improve and optimize the photoluminescence property for applications such as toxic molecule detection ${ }^{31}$ and biolabeling. ${ }^{32}$ Only a few studies thus far have reported some intriguing insights into the structure of protein-Au NCs and how they are formed under the influence of the protein ${ }^{33-35}$. This review will begin with the synthesis of protein-stabilized Au NCs and then move into the recent investigations of their structure. The final section will explore viable fluorescence applications that have been reported in the literature and the outlook for protein-Au NCs.

\section{Synthetic Methods}

Thiol-capped Au NPs have been extensively studied in many fields of nanotechnology because of strong $\mathrm{Au}-\mathrm{S}$ interactions on the NP surface, leading to highly stable Au NPs. ${ }^{12,36-38}$ Proteins, such as lysozyme and bovine serum albumin, containing sulfur-bearing amino acids, have been functionalized as nanoparticle thiol-capping agents a few years prior to the intense investigation of nanoclusters. ${ }^{39-41}$. This demonstration of protein-assembled nanostructures, along with many earlier contributions, ${ }^{28,29}$ excited the field of nanotechnology with the new idea of forming nanoparticles in protein templates. However, understanding how these highly ordered structures synthesize nanoparticles is demanding, requiring an extensive knowledge of proteinnanoparticle interactions. ${ }^{42,43}$ Some recent contributions will be discussed.

Biomineralization is a natural process in which biological organisms intake metal species to subsequently form mineral structures. Stimulated by this process, research has shown that nanostructures can be formed when harnessing the biological organism's or macromolecule's ability to naturally intake and arrange inorganic materials. ${ }^{44-47}$ From this previous fundamental work, incorporating proteins with gold atom precursors has evolved into a new branch of one-pot syntheses, producing stable and fluorescent Au NCs. This pathway for synthesizing nanoparticles and nanoclusters has been referred to as "protein/peptide-directed," "biomineralization," and "protein-stabilized," to name a few. There are many advantages to this one-pot synthetic 
approach, including its relatively low environmental impact, which is very attractive in today's environmentally conscience world. ${ }^{48}$ Mild reaction conditions, aqueous solution chemistry, and absence of strong reducing agents make the formation of Au NCs a green chemical synthesis. Quite often, only $\mathrm{pH}$ conditions in the reaction are altered to optimize the protein's reducing ability or to change the conformation to increase organic-metal bonding and stabilization. A typical reaction pathway for a protein-directed synthesis is shown in Fig. 2.

Since the protein plays a vital role of stabilizing, reducing, and arranging gold atoms into stable nanoclusters, the formation of a single Au NC product is highly dependent on the conformation of the protein. ${ }^{33}$ A highlight of these water-soluble Au NCs is how readily they can be used in applications because of their immediate biocompatibility. Already, many proteins have been used as stabilizing agents for Au NCs such as BSA,${ }^{49-54}$ lysozyme, ${ }^{55,56}$ human transferrin, ${ }^{57}$ lactoferrin ${ }^{58}$ tryspin,${ }^{59}$ pepsin,${ }^{60}$ insulin, ${ }^{61}$ and horseradish peroxidase. ${ }^{62}$

It is already known that select amino acids can play a key role in nanoparticle synthesis due to their reducing strength and/or favorable binding interactions with gold. ${ }^{63,64}$ When amino acids are randomly organized in peptide strands, only certain sequences of amino acids can promote nanoparticle growth while others will have little interaction with metal ions. ${ }^{65,66}$ Working toward this end, a "bottom-up" study performed by Lee et al ${ }^{67}$ tested all 20 amino acids to determine their reducing and binding capabilities when interacting with $\mathrm{HAuCl}_{4}$. After documenting the ability of each individual amino acid, combinations of active amino acids were synthesized into peptide chains to capture the effect of neighboring amino acid residues in a secondary conformation. Tryptophan was identified for being the strongest reducing agent and was therefore interdigitated into custom peptides for its reducing property. In a similar fashion, histidine was selected as the strongest metal binding amino acid and was also interdigitated into another set of peptides. From these preliminary peptide results, more diverse combinations with other amino acids were investigated to determine the resultant shape and size of the Au NPs, along with tracking the periods of reaction initiation, growth, and termination.

The increase in complexity from small peptides to larger protein systems is extremely significant. In a few studies of protein-stabilized Au NCs and NPs, structural changes of proteins have been detected using techniques such as UV-Vis, circular dichroism, infrared and mass spectrometry. ${ }^{33,35,43} \mathrm{Pal}$ et al ${ }^{33}$ proposed an interesting scheme for how the growth of protein-Au NPs could be an autocatalytic process, where the protein initially reduces gold atoms to form a Au NP seed, which then promotes further $\mathrm{Au}^{+}$intake into the protein. This study used human serum albumin, subtilisin Carlsberg, and an E. coli extract to obtain kinetic parameters for Au NP formation. From this kinetic data and other proteins tested, they also proposed that the induction period length for initializing Au NP growth could be influenced by the protein's melting temperature, a useful insight for optimizing the formation of Au NPs and Au NCs.

\section{Structural Investigations}

\subsection{Standard Characterization Methods}

A wealth of techniques have been developed and applied for understanding Au NPs over the past few decades. From these well-established methods, only some have proved useful for

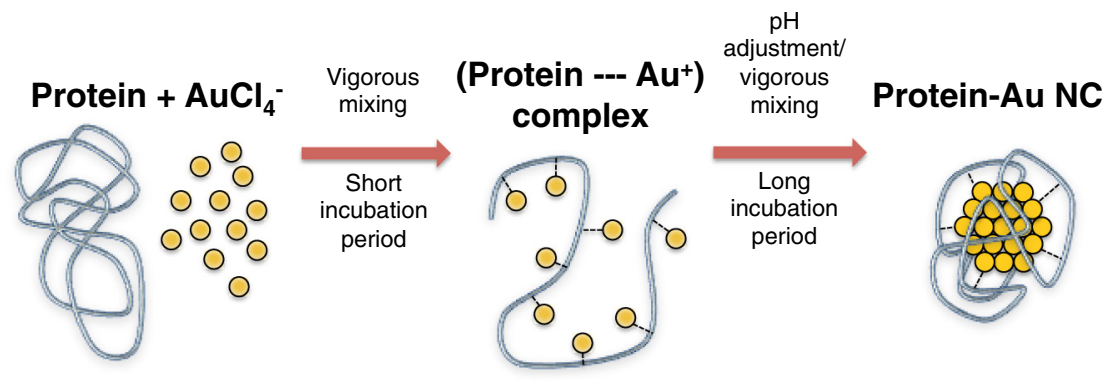

Fig. 2 This reaction scheme illustrates the facile synthetic route for producing Au NCs with selected proteins that promote NC growth and formation. 
investigations of protein-Au NCs. For instance, because of magnification limitations for transmission electron microscopy (TEM), Au NCs are not as easily imaged as Au NPs. Highresolution TEM can be attempted to detect Au NC size at the subnanometer level but is not always successful. In particular, Au NC species smaller than 25 gold atoms have been difficult to observe. ${ }^{60}$

Conventional spectroscopies, such as UV-Vis and fluorescence, are essential in protein-Au $\mathrm{NC}$ studies to capture their optical properties. However, protein-Au NCs are too small to exhibit surface plasmon resonance (SPR); therefore, no absorption features in the visible region clearly detect the presence of Au NCs. Fluorescence spectroscopy is, of course, imperative for reporting excitation and emission wavelengths, as well as fluorescence lifetime events. Infrared and circular dichroism spectroscopy can be useful for identifying changes to the protein structure before and after synthesis, confirming any protein denaturation. In addition to these standard characterization techniques, more robust methods are providing valuable information on the structural environment of protein-Au NCs.

\subsection{Structural Determination by Mass Spectrometry}

An important characterization tool for the elucidation of thiol-capped Au NCs is mass spectrometry. ${ }^{15,37,68}$ Mass spectrometry alone can provide reliable structural details, such as determining the size of the gold core and capping ligand environment. Obtaining these parameters can lead to a quantitative analysis of $\mathrm{Au} \mathrm{NC}$ composition. Determining the precise sizes of the $\mathrm{Au}_{m}(\mathrm{SR})_{n}$ ( $R=$ organic capping ligand) magic cluster series has initiated major breakthroughs in quantum calculations of nanoclusters, leading to thorough explorations of their electronic structure. ${ }^{1,14}$ Numerous articles continue to be published, revealing interesting properties and potential applications for the $\mathrm{Au}_{m}(\mathrm{SR})_{n}$ cluster. After the introduction of the first protein-Au NCs, mass spectrometry was proven to be an important tool for identifying cluster sizes inside the capping protein. It has also been shown to be a good technique for tracking the formation of Au NCs. ${ }^{69}$

There has been some speculation surrounding the actual size of the protein-Au NCs to determine if they are indeed magic clusters (i.e., $\mathrm{Au}_{25}$ or $\mathrm{Au}_{38}$ ). So far, protein-Au NCs have been reported as both single magic clusters ${ }^{49,52,60}$ and a distribution of cluster sizes ${ }^{54,57,58}$ This discrepancy could stem from the difference in the protecting protein. Nevertheless, further research is needed to make such conclusions.

One study ${ }^{35}$ utilized matrix-assisted laser desorption ionization mass spectrometry (MALDIMS) to document the $\mathrm{pH}-d e p e n d e n t$ and time-dependent in situ growth of Au NCs in BSA and native lactoferrin protein. From this insightful study, MALDI-MS results highlighted the importance of $\mathrm{pH}$ and reaction time on the protein's reducing and stabilizing ability. With neutral $\mathrm{pH}$ levels, $\mathrm{Au}^{+}$was found to bind with the protein as a complex with only 13 to 14 gold atoms found in the cluster. At an alkaline $\mathrm{pH}$ level $(\sim 12)$, which is commonly used in protein-directed syntheses, ${ }^{49,55}$ further reduction to $\mathrm{Au}^{0}$ was observed leading to larger clusters forming around 25 gold atoms. Some interesting observations were the presence of free, unreacted proteins as well as $\mathrm{Au}^{+}$ions that were redistributed at different times in the reaction. Without the addition of $\mathrm{NaOH}$ to the lactoferrin protein and $\mathrm{Au}^{3+}$ ion mixture, only 17 gold atoms were found in the product. Adding $\mathrm{NaOH}$ to the mixture produced a 25 gold atom product after $8 \mathrm{~h}$. After $24 \mathrm{~h}$ the same reaction mixture had amounts of unreacted protein along with the 25 gold atom Au NC, indicating that redistribution of $\mathrm{Au}^{+}$ions is evident in the protein-directed process.

\subsection{Structural Determination by $X$-ray Techniques}

On the topic of probing the structure of protein-Au NCs, there are x-ray spectroscopy techniques that offer a site-specific determination of local structure for Au NCs. A few x-ray spectroscopies are mentioned below to discuss how they are indispensible for uncovering protein-stabilized $\mathrm{Au}$ $\mathrm{NC}$ structure and understanding the protein-directed process.

One technique commonly seen in Au NC and NP research is x-ray photoelectron spectroscopy (XPS). Examining the $4 \mathrm{f}_{7 / 2}$ and $4 \mathrm{f}_{5 / 2}$ binding energies of protein-stabilized Au NCs is an excellent method for determining the size and overall oxidation state of gold by comparing spectra to $\mathrm{Au}^{+}$-thiol ligand and gold foil. Peak fitting of XPS spectra can determine a quantitative 
measurement for composition. Standard in a number of $\mathrm{Au} N C$ studies is the $4 f_{7 / 2}$ and $4 f_{5 / 2}$ peaks will often lie between $\mathrm{Au}^{+}$and $\mathrm{Au}^{0}$, indicating a compositional mixture of a $\mathrm{Au}^{0}$ core with surface $\mathrm{Au}^{+}$atoms. Many of the red-emitting Au NCs found in the literature have anywhere from $10 \%$ to $25 \%$ of $\mathrm{Au}^{+} .^{54,57,61}$ The binding energy of the $4 \mathrm{f}$ peaks will also shift to a higher energy as the $\mathrm{Au} \mathrm{NC}$ size shrinks. ${ }^{70}$ Contrary to the $\mathrm{Au}_{25} \mathrm{NC}$, only $\mathrm{Au}^{0}$ composition is detected for blue-emitting $\mathrm{Au}_{8}$ clusters with no gold-thiol bonding indicated at the $\mathrm{S} 2 \mathrm{p}$ peaks. ${ }^{54}$ It was hypothesized that the $\mathrm{Au}_{8}$ cluster is loosely held inside the protein. A comparison is shown in Fig. 3.

Y. Lu et al. undertook a remarkable study ${ }^{34}$ gaining a mechanistic point of view of how a protein and metal precursors interact to produce gold nanoparticles. Recent convention for synthesizing protein- $\mathrm{Au} \mathrm{NCs}$ has been to start with $\mathrm{Au}^{3+}$ salt and protein in solution. ${ }^{49,55} \mathrm{How}-$ ever, this study used a single native lysozyme crystal with incorporated $\mathrm{Au}^{+}$salt to observe the time-dependent arrangement of gold inside the protein crystal by achieving slower kinetic formation of nanoparticles. With x-ray crystallography and electron microscopy, the distribution and arrangement of gold atoms inside the lysozyme were tracked over several days, observing a disproportionation of $\mathrm{Au}^{+}$to $\mathrm{Au}^{3+}$ and $\mathrm{Au}^{0}$, where $\mathrm{Au}^{0}$ accumulates to yield larger $\mathrm{Au}$ NPs up to $20 \mathrm{~nm}$ (Fig. 4). The amino acid residue histidine is an accumulation source for $\mathrm{Au}^{+}$before it becomes disproportionated. This observation deems histidine a vital component for the proteindirected growth of Au NCs and NPs. This study created a new vision for observing bio-nano hybrid systems and identifying important functional residues of the protein crucial for gold nanoparticle and nanocluster growth.

X-ray absorption spectroscopy (XAS) can determine structural parameters of a chemical system from an element-specific perspective. It can be broken down into two parts: x-ray absorption near-edge spectroscopy (XANES) and x-ray absorption of fine structure (XAFS). In a typical experiment, a polychromatic light source (obtained from synchrotron radiation) is tuned to excite

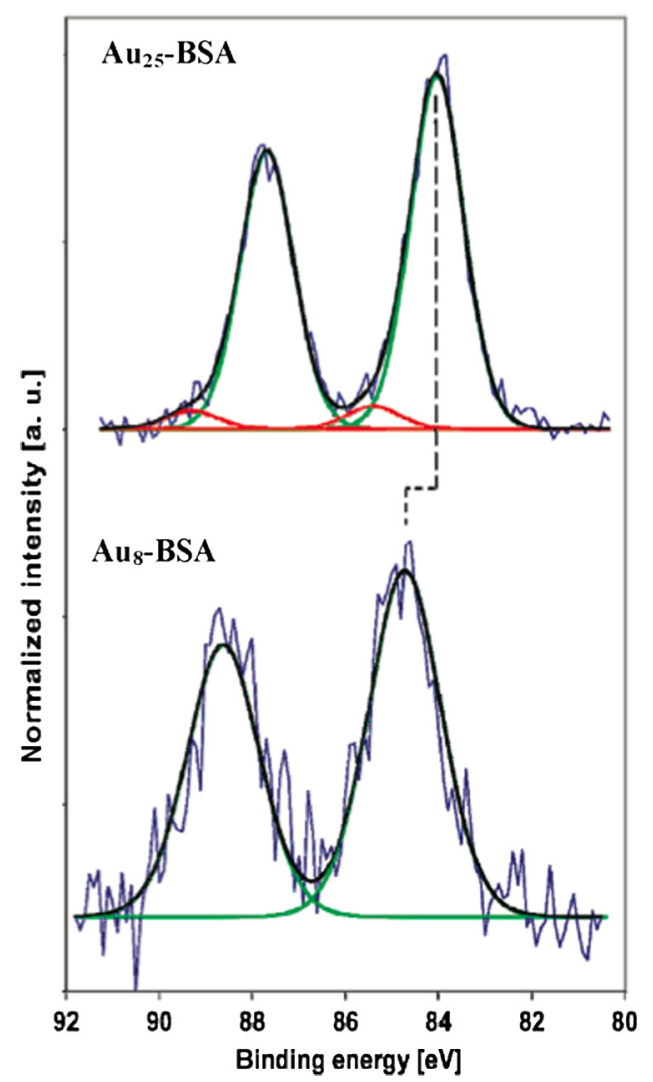

Fig. 3 XPS spectra of the $\mathrm{Au} 4 \mathrm{f}$ band for $\mathrm{BSA}-\mathrm{Au}_{25}$ and $\mathrm{BSA}-\mathrm{Au}_{8}$. A shift in higher binding energy is seen for smaller clusters. From peak fitting of each band, mostly $A u^{0}$ is only seen for $A u_{8}$ where $\mathrm{Au}_{25}$ has some $\mathrm{Au}^{+}$contribution, likely from the NC surface. (See Ref. 55). 


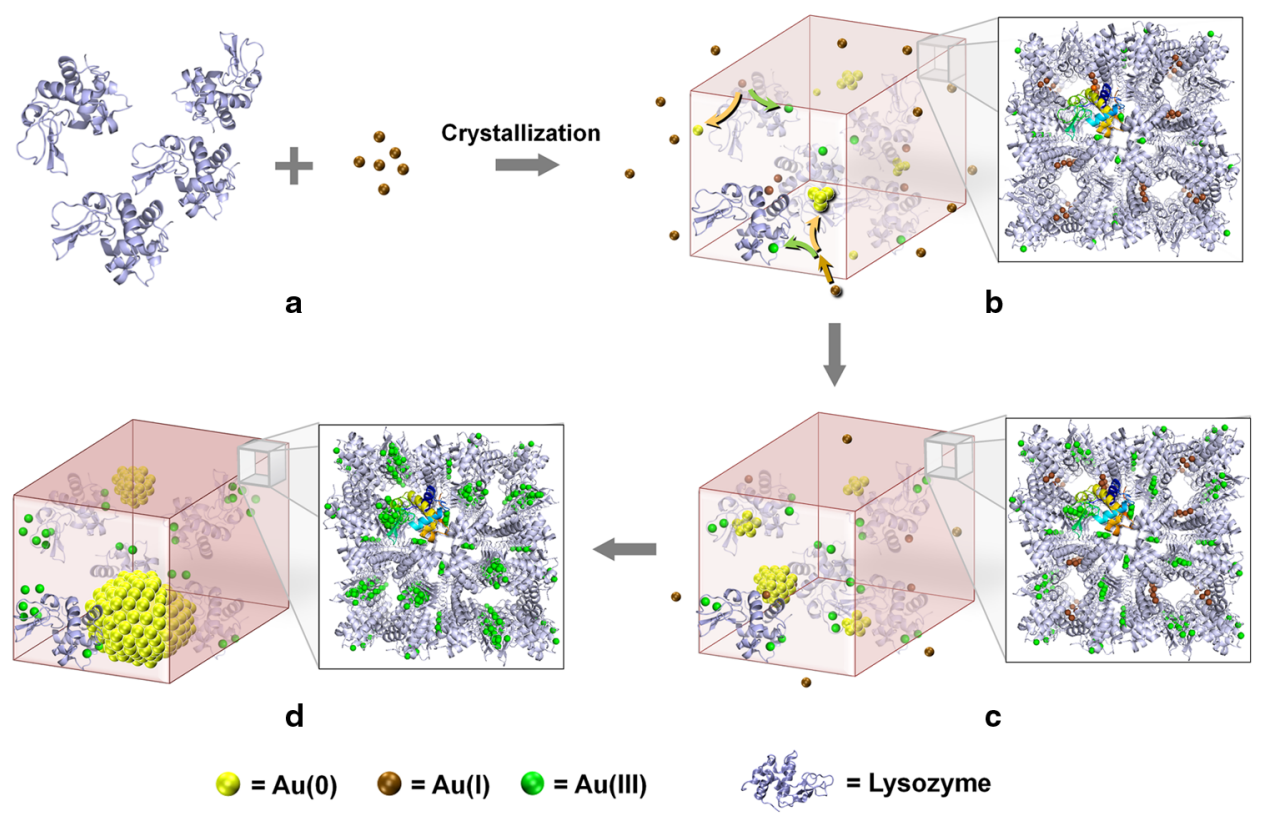

Fig. 4 A schematic representation of $\mathrm{Au}^{+}$disproportionating to form Au NPs in a lysozyme crystal. (See Ref. 34).

the core electrons of a certain element (i.e., gold), which then emits a photoelectron wave interacting with the surrounding atoms in its bonding environment. The resulting re-absorption from the returning photoelectron wave contains information about the number of surrounding atoms, their element type, and bond lengths. Zhang et al. ${ }^{22}$ used these techniques, along with complementary calculations to compare the electronic structure between the BSA-stabilized Au NC and the known $\mathrm{Au}_{25}(\mathrm{SR})_{18}$ cluster. From structural refinement results and comparison to previous $\mathrm{Au}_{25}(\mathrm{SR})_{18}$ results, it was determined that the BSA-stabilized cluster may also have the unique surface staple structure as seen in the $\mathrm{Au}_{25}(\mathrm{SR})_{18}$ cluster. Also from this study, densities of states (DOS) calculations were done to illustrate the electronic influence from the staple structure compared to that of the nanocluster core. The difference between the surface staple and the core has a dramatic effect on the entire cluster, which helps explain the interesting properties Au NCs behold. Additional research remains to confirm the existence of the surface-staple in fluorescent protein-Au NCs.

A recent study synthesized paired Au NCs inside a ferritin protein enhancing and red-shifting the fluorescence compared to a single unpaired Au NC. ${ }^{71}$ This group examined XANES spectra at the $\mathrm{Au} L_{3}$-edge of Au-amino acid mixtures, Au NPs and their synthesized paired ferritin-Au NCs. Comparing the edge-shift from XANES and binding energy from XPS, they were able to determine the $\mathrm{Au}^{0} / \mathrm{Au}^{+}$composition as well as confirm the important role of histidine in the reduction and formation of ferritin-Au NCs.

\section{Optical Properties and Potential Applications}

\subsection{Gold Nanocluster Optical Properties}

Protein-stabilized Au NCs are being recognized for their strong fluorescence in the visible spectrum. The discovery of Au NC photoluminescence was reported earlier, stating that luminescence will intensify with decreasing nanoparticle size. ${ }^{4}$ This transition can be seen where SPR from Au NPs diminishes and photoluminescence occurs at the Au NC size regime.

It is known that the photoluminescence property is attributed to molecular-like transitions between HOMO-LUMO energies ${ }^{1-3}$ due to their ultra-small size. In result, the interband radiative transition lifetime is very short for $\mathrm{Au} \mathrm{NCs}$, ranging from picoseconds to nanoseconds. ${ }^{72}$ Dickson et al. has provided many investigations of dendrimer-stabilized Au NCs 
exhibiting a wide fluorescence range. ${ }^{3}$ Dickson's work has demonstrated that Au NCs closely follow the jellium model when determining transition energies. They have also shown the size-dependent effect on surface potentials as the potential wells change from a spherical harmionic (Au NCs) to a square well (Au NPs). ${ }^{2}$ In these experiments it was observed that quantum yields were as high as $70 \%$ for $\mathrm{Au}_{5}$ to $10 \%$ for $\mathrm{Au}_{31}$, all having fluorescence lifetimes of a few nanoseconds. However, these results are from dendrimer-encapsulated Au NCs. Varying the capping molecule can dramatically affect the fluorescence properties of the Au NC system. To explore the effects of the protecting molecule on fluorescence properties, investigations are under way.

Sakanaga et al. ${ }^{73}$ investigated excited energy emission bands of the $\mathrm{Au}_{25}$ nanocluster and isolated two luminescence transitions, one band between 6sp states and the excited band between $6 \mathrm{sp}$ and $5 \mathrm{~d}$ states. Work from Jin et al. ${ }^{25}$ prepared the $\mathrm{Au}_{25}$ cluster capped with various ligands and demonstrated the trend of increasing fluorescence intensity by ligand's ability to donate electron density to the $\mathrm{Au} \mathrm{NC}$ surface. The total oxidation state of $\mathrm{Au}_{25}(\mathrm{SR})_{18}$ was shown to influence the luminescence intensity as it increases with a more positive oxidation level on the cluster. Based on ongoing research, more can be achieved in order to maximize quantum yields and understand the origin of fluorescence.

\subsection{Sensing Applications}

The detection of toxic metals $\left(\mathrm{Hg}^{2+}, \mathrm{Cd}^{2+}, \mathrm{Pb}^{2+}\right)$ in solution is a possible analytical application for Au NPs. ${ }^{74-77}$ It is shown that interactions with heavy metal ions can be detected by changes in the UV-Vis absorption due to the aggregation or chelation of Au NPs. ${ }^{78,79}$ Therefore, Au NPs can serve as colorimetric assays for toxic metal detection. More recently, Au NCs capped with proteins and other biomolecules have also been employed for selective detection of metals as an application.

Experimenting with BSA has been a perfect starting point for researchers to study protein-Au $\mathrm{NC}$ systems. Xie et al. ${ }^{49}$ ignited this interest for using BSA when they introduced a facile proteindirected synthesis, which was subsequently adopted by many research groups for other protein$\mathrm{Au}$ NC systems. BSA has been used previously ${ }^{42,43}$ as a capping agent for Au NPs but not in a biocompatible fashion. As a result of this accessible synthesis, a surge of BSA-Au NC studies emerged. ${ }^{50-54}$ Red emission from BSA-Au NCs occurs around $640 \mathrm{~nm}$ with quantum yields reported as high as $6 \%$ (see Fig. 5). ${ }^{49,51}$ The BSA-Au NC was found in a few reports ${ }^{50,54,80}$ to have a selective interaction with $\mathrm{Hg}^{2+}$ species. This interaction quenches the fluorescence linearly with increasing $\mathrm{Hg}^{2+}$ concentration. It has also been shown that BSA-Au NCs can detect other metals such as $\mathrm{Cu}^{2+} .^{52}$
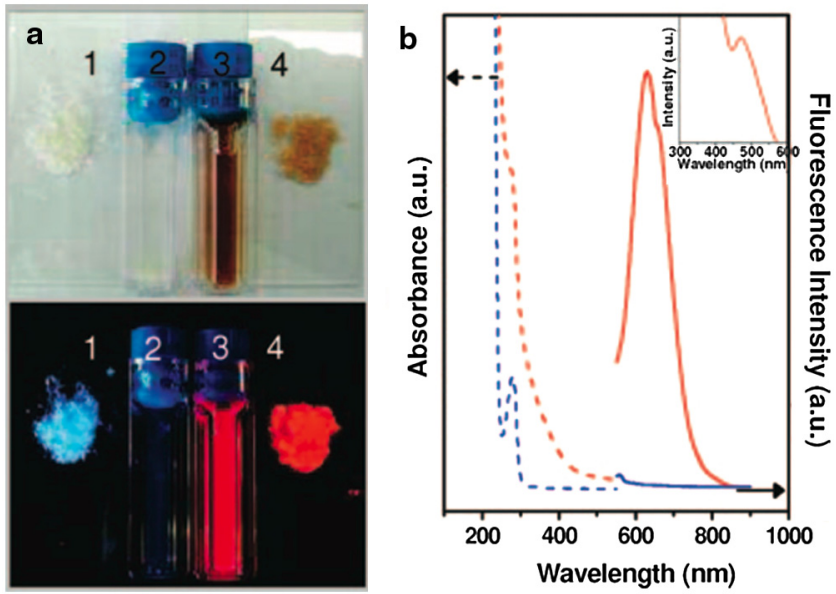

Fig. 5 Comparison between BSA (blue) and red-emitting BSA-Au NC (red), both in solution and in lyophilized form. The absorption spectra are the dashed lines and fluorescence spectra are the solid lines. Inset image is the excitation spectrum of BSA-Au NC. See Ref. 48). 
There have been a few proposed mechanisms for fluorescence quenching discussed in the literature. One suggested mechanism is that highly metallophilic bonding between the $\mathrm{d}^{10}$ centers, $\mathrm{Hg}^{2+}$ and $\mathrm{Au}^{+}$, disrupts the fluorescence from Au-BSA interactions. ${ }^{80}$ The second proposed mechanism is a photo-induced electron transfer process. In this process, $\mathrm{Hg}-\mathrm{S}$ bonds are formed from BSA, which then intercepts one of the charge carriers during the excitation process, reducing $\mathrm{Hg}^{2+}$ to $\mathrm{Hg}^{+}$. It is thought that the latter species creates interference, thereby quenching the fluorescence. ${ }^{50}$ Cyanide etching is one known process that will quench BSA-Au NC fluorescence by removing gold atoms from the gold core. ${ }^{81}$ Most detection limits for sensing applications have been very low, ranging from $80 \mathrm{nM}^{50}$ to $0.5 \mathrm{nM}^{80}$ ultrasensitive for determining toxic metal concentrations in an environmental setting. ${ }^{81}$ Another study ${ }^{53}$ has employed BSA-Au NCs for the biodetection of glutaraldehyde with a detection limit of $0.2 \mu \mathrm{M}$. This fluorescence-quenching event is caused by crosslinking between BSA and glutaraldehyde.

Another protein of choice for experimentation with bio-nano systems is lysozyme because of its commercial availability and antibacterial properties. Lysozyme has been confirmed to synthesize Au NCs in a protein-directed process with near IR fluorescence. Like BSA, it is no surprise that lysozyme would be a good candidate for nanocluster growth as it has already been employed for synthesizing Au NPs ${ }^{39,82,83}$ One of the first lysozyme-stabilized Au NC was synthesized by Lu et al. ${ }^{55}$ reporting an emission wavelength of $657 \mathrm{~nm}$ and a quantum yield of 5.6\%. The application of $\mathrm{Hg}^{2+}$ detection was also proven to be viable with a detection limit of $10 \mathrm{nM}$, comparable to Xie et al. ${ }^{80}$ with $0.5 \mathrm{nM}$. Indeed, lysozyme-Au NCs have the $\mathrm{Hg}^{2+}$ detection ability despite difference in protecting protein. Taking the lysozyme-Au NC one step further, one group was able to synthesize similar clusters to the previous study on an eggshell membrane, which contains the lysozyme protein high in cysteine units. ${ }^{56}$ Again, a green protein-directed approach is used. This study's results produced Au NCs on a solid-state platform with near IR emission similar to Lu et al. ${ }^{55}$ This group proposed applications for this fluorescent nanomaterial such as recyclable catalysts and chemical sensing paper.

Since the initial breakthrough of using BSA and lysozyme, other biomolecules of various sizes have successfully synthesized fluorescent Au NCs, which also exhibit detection capabilities. Au NCs stabilized with the amino acid 1-cysteine ${ }^{72}$ showed fluorescence emission in the blue end of the visible spectrum $(\sim 350 \mathrm{~nm})$ and was used as a detection probe for glucose sensing. This study also tested for glucose levels in serum samples with selective detection avoiding interference from other serum proteins. Glutathione was used as a stabilizing biomolecule, ${ }^{84}$ producing similar red emission to BSA and lysozyme Au NCs but with an emission wavelength further red-shifted, correlating with the larger size of the observed nanocluster $(\sim 2 \mathrm{~nm})$. Glutathione-stabilized Au NCs showed fluorescence quenching from $\mathrm{Cu}^{2+}$ ions and good stability against photobleaching and oxidation, making them potential bio-imaging probes. The iron-binding protein lactoferrin stabilized red-emitting Au NCs while also being useful for detecting $\mathrm{Cu}^{2+}$ ions. ${ }^{58}$ Fluorescence quenching was minimal with the addition of iron ions, indicating the lactoferrin protein structure was relatively undisturbed in the final product. The lactoferrin-Au NC also exhibited good stability at various $\mathrm{pH}$ levels, maintaining strong fluorescence. This study investigated the specific region where the Au NC formed in the lactoferrin by using Förster resonance energy transfer (FRET). This technique detects energy transfers from excited donors to acceptors, which can reveal the energy transfer efficiency and the nature of the bonding between lactoferrin and the Au NC. Another protein, trypsin, can be used as a stabilizing agent for $\mathrm{Au} \mathrm{NCs}{ }^{59}$ with red emission at $640 \mathrm{~nm}$, selective $\mathrm{Hg}^{2+}$ detection, and resistance to photobleaching. The stability against photobleaching was comparable with CdSe quantum dots, making them a relatively nontoxic alternative for bio-imaging.

Besides quenching the fluorescence in order to detect other species, protein-Au NCs have been able to detect other metal species with metal-enhanced fluorescence or luminescence (MEF or MEL) ${ }^{52,60,80}$ This event occurs when metal NPs are close in space but not directly bound to the fluorophore. Enhanced fluorescence from metal species is due to a number of effects, such as altering the radiative decay rate and increasing the absorption of the fluorescing molecule. ${ }^{85}$ In the case of protein-Au NCs, the protein acts as a boundary layer between the NPs or other metals and $\mathrm{Au} \mathrm{NC}$ to enhance the fluorescence. Examples of MEF or MEL with protein- $\mathrm{Au} \mathrm{NCs}$ are the detection of $\mathrm{Ag} \mathrm{NPs}, \mathrm{Ag}^{+}$and $\mathrm{Pb}^{2+52,60,80}$ 


\subsection{Tunable Emission}

In the preceding section, most of the protein-stabilized Au NCs discussed have red to near IR fluorescence originating from $\mathrm{Au}$ NCs with an average size of 25 gold atoms. It was found that if $\mathrm{Au} \mathrm{NCs}$ are synthesized to extremely small $\mathrm{Au}_{8}$ clusters (sometimes called nanodots) with dendrimers or an etching process ${ }^{5,86,87}$ they will exhibit intense blue fluorescence. Here arises an interesting structure-property relationship between $\mathrm{Au}$ NC size and their emission wavelength where the fluorescence blue shifts with a decreasing number of gold atoms in the cluster. Proteinmediated synthesis proves to be quite flexible, especially when subtle changes to the reaction can yield modified $\mathrm{Au}$ NCs with different emission properties. An example of this is a study ${ }^{54}$ where $\mathrm{Au}_{8} \mathrm{NCs}$ were synthesized with BSA by lowering the $\mathrm{pH}$ to 8 . This is a slight change in $\mathrm{pH}$ from the original $\mathrm{pH}$ of 11 to 12 for red-emitting $\mathrm{Au}_{25} \mathrm{NCs}$ in BSA. The emission wavelength for $\mathrm{Au}_{8}$ NCs was $450 \mathrm{~nm}$, comparable to the previously synthesized blue $\mathrm{Au}_{8} \mathrm{NCs}$ but with a quantum yield that is slightly lower, around 6\%. Other small Au NCs were synthesized in another study ${ }^{88}$ with an emission wavelength of $490 \mathrm{~nm}$ (bluish-green) and a declared size for the cluster of $\mathrm{Au}_{10}$. These NCs were not encapsulated by a large biomolecule but stabilized by histidine. All of these blue-emitting Au NCs have shown high quantum yields and could be accessible for bio-imaging purposes.

Similar to the $\mathrm{pH}$-modified synthesis of BSA-Au NCs to yield $\mathrm{Au}_{8}$, a recent study demonstrated how the gastric peptide pepsin could be adaptable to produce blue, green, and red fluorescent $\mathrm{Au} \mathrm{NCs},{ }^{60}$ schematic shown in Fig. 6. In alkaline $\mathrm{pH}$ conditions, red-emitting $\mathrm{Au}_{25} \mathrm{NCs}$ were stabilized by pepsin, similar to BSA and lysozyme. Strong acidic conditions produced $\mathrm{Au}_{13}$ NCs stabilized by autolytic peptide strands from pepsin with a subsequent green fluorescence. To reduce the core size to blue-emitting $\mathrm{Au}_{8}$ and $\mathrm{Au}_{5}$, a dramatic jump to higher $\mathrm{pH}$ effectively etched the $\mathrm{Au}_{13}$ core to this final size. XPS was used to compare the $4 \mathrm{f}$ peaks for $\mathrm{Au}_{8}, \mathrm{Au}_{13}$, and $\mathrm{Au}_{25}$, which showed increasing binding energy with reduced core size. The effect of Au NC size on the fluorescence emission energy is presented well in this study. This protein-directed route for pepsin was successful for utilizing various conformations and, in this case, cleaved residues to synthesize an array of $\mathrm{Au} \mathrm{NCs}$. The $\mathrm{Au}_{25} \mathrm{NC}$ was shown to be useful for the detection of $\mathrm{Hg}^{2+}$ and $\mathrm{Pb}^{2+}$ by fluorescence quenching and fluorescence enhancement, respectively.

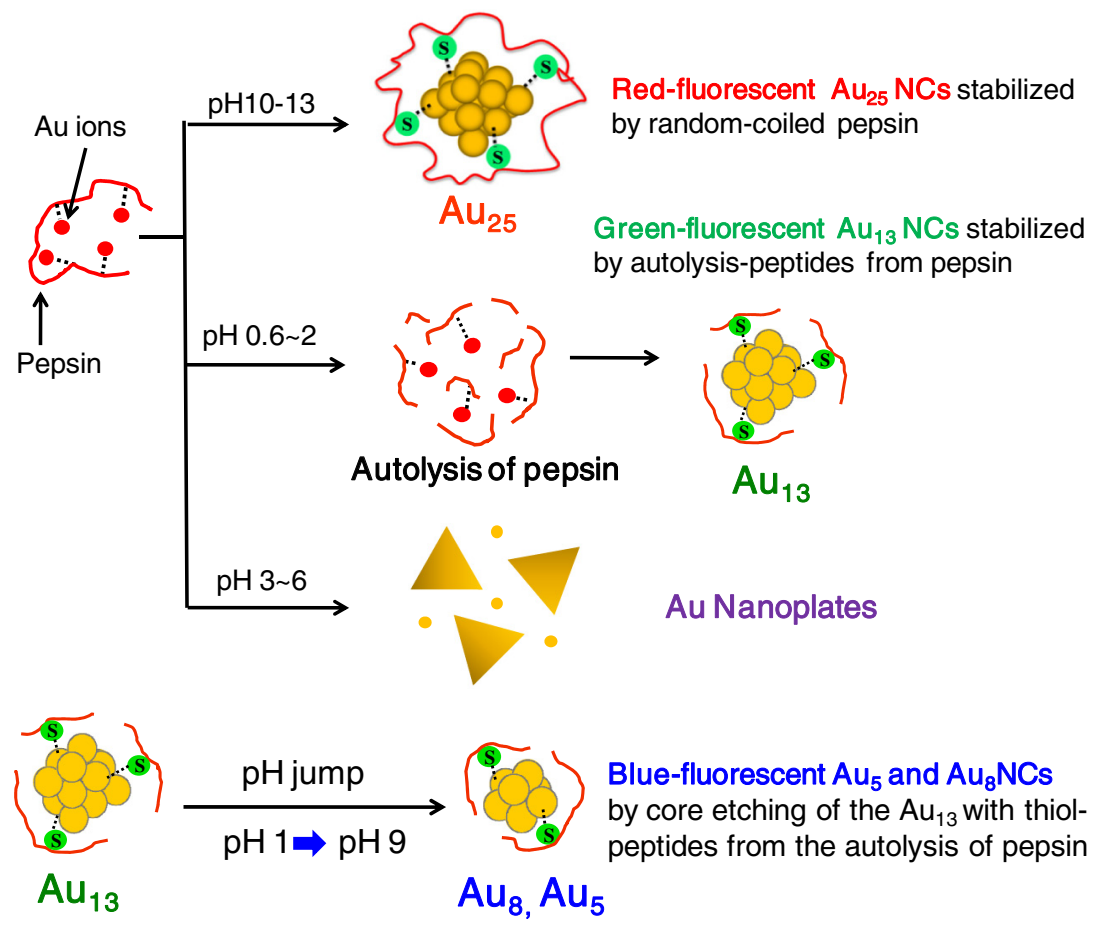

Fig. 6 Effect of $\mathrm{pH}$ on the Au NC product when using the gastric peptide pepsin. (See Ref. 59). 


\subsection{Biolabelling and Targeted Imaging Applications}

Returning to the BSA-Au NC, highlighted in this review, a couple of studies ${ }^{51,52}$ released shortly after Xie et al. ${ }^{49}$ were able to conjugate folic acid to the surface of BSA through amine linkages. These studies used Au NCs as an imaging probe for detection of folate receptors on ( + ) oral carcinoma cells with an emission profile extending into the near-IR, suitable for tissue penetration. Results reveal these Au NCs as nontoxic and a viable method for selectively detecting and imaging cancer cells since only a minor reduction in the quantum yield was detected after the bioconjugation of folic acid. From this study, it could open possibilities to conjugate linkages in the BSA structure for other receptor-targeting biomolecules for targeted imaging applications.

The protein-directed synthesis was adapted to produce human apo-transferrin-stabilized $\mathrm{Au}$ NCs with strong emission in the near IR region for cell imaging and targeting. ${ }^{57}$ As described previously, reducing agents are avoided for protein-directed syntheses to improve biocompatibility and retain native protein structure. In this study, however, the mild reducing agent ascorbic acid was added to aid the reduction of gold ions without adding excessive amounts of protein. The iron-free apo-transferrin protein initially stabilized the $\mathrm{Au}$ NC with iron added afterwards to determine if apo-transferrin maintains its natural iron-binding ability. The addition of iron was found to have little effect on the fluorescence of the Au NC, indicating preservation of the transferrin protein. A cell study demonstrated transferrin-Au NCs can enter lung tumor cells and maintain strong red fluorescence. High stability against photobleaching, changes in solution $\mathrm{pH}$, and different buffer systems were also reported. From this study alone, a new protein-stabilized Au NC was synthesized with immediate applications for targeting and imaging cancer cells.

On the topic of preserving protein functionality, insulin has been successfully utilized as a stabilizing agent for red-emitting Au NCs. ${ }^{61}$ However, insulin lacks cysteine residues, therefore very few $\mathrm{Au}-\mathrm{S}$ bonds are present in the structure so other amino acids must exercise their binding ability to stabilize the Au NC. The size from HRTEM images indicated a particle size of $\sim 1 \mathrm{~nm}$, where MS data was unable to confirm the composition. Interestingly, we still see a comparable fluorescence emission profile to other protein-Au NCs and a large amount of $\mathrm{Au}^{0}$ with small surface composition of $\mathrm{Au}^{+}$, determined from XPS. Insulin-Au NCs showed great biocompatibility and cell internalization (see Fig. 7). During cell studies, it was found that insulin-Au NCs could also be used as a contrasting agent for computed tomography along with fluorescence
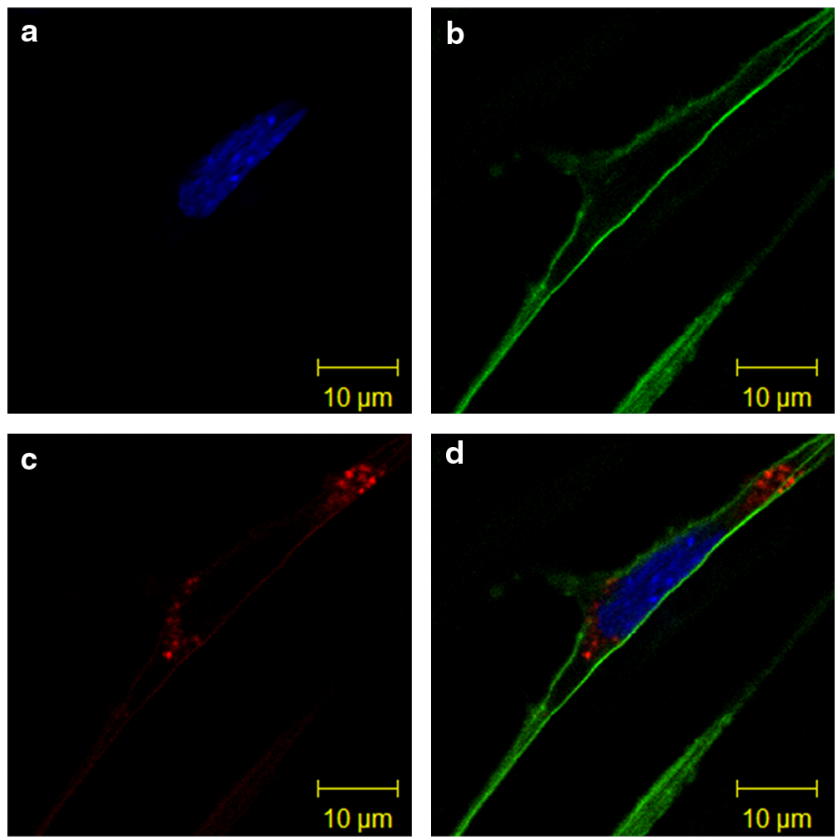

Fig. 7 Internalization of fluorescent insulin-Au NCs inside myoblast cells. The as-prepared Au NCs retain their strong red fluorescence inside the cell. Fluorescent staining of the cell nucleus (blue) and cell wall (green) is also shown. (See Ref. 60). 
imaging, making these Au NCs a dual functioning imaging probe. As for the bioactivity, insulinAu NCs were comparable to commercially available insulin in lowering the blood glucose levels in small animal tests. Many impressive features of the insulin-Au NC have been shown and hold great potential for future biomedical technology.

The enzymatic protein, horseradish peroxidase, successfully stabilized fluorescent Au NCs. ${ }^{62}$ The horseradish peroxidase enzyme proved to be a good stabilizing agent for the growth of $\mathrm{Au} \mathrm{NCs}$ with appreciable red fluorescence. It was observed that the enzyme retains its enzymatic ability to breakdown $\mathrm{H}_{2} \mathrm{O}_{2}$, leading to quenching of the Au NC fluorescence. TEM and XPS results indicated there was Au NC aggregation leading to larger Au NPs, consequently quenching the fluorescence.

These examples of protein-Au NCs serving as biolabeling and imaging probes demonstrate the multifunctional abilities capable for immediate biomedical applications. Advantages for using protein-Au NCs over other fluorescent nanomaterials are their water solubility, low toxicity, and facile synthesis, excluding harsh reducing agents or organic solvents. Protein-Au NC systems are also multifunctional, enabling further modifications of its structure by conjugating additional biomolecules to its surface. For example, work done with red light-emitting dihydrolipoic acid capped Au NCs demonstrated the versatile nature of these systems. ${ }^{89}$ Instead of directly stabilizing the Au NC with proteins (mainly discussed in this review), a bioconjugation step attached functional biomolecules such as BSA, PEG, avidin, and streptavidin. This study presented Au NCs enduring a number of synthetic steps while preserving strong luminescence and stability while also exploiting the bioconjugated Au NCs as a biolabeling agent. Additional studies exploring the functionality of the capping environment are anticipated, especially for targeted imaging and drug delivery applications.

\section{Conclusions and Outlook}

The study of protein-Au NCs is evidently a quickly evolving field in nanotechnology. Several proteins and other biomolecules are successful stabilizing agents for Au NCs yielding highly stable products with promising light-emitting applications. Protein-Au NCs presented in this review have shown very low detection limits for fluorescence quenching detection, good photostability for biolabeling/imaging purposes and in some cases, preservation of native protein structure to retain biological activity. With green chemical syntheses of these nanomaterials, researchers will able to conduct in-depth studies investigating biomedical applications without further biocompatibility preparations. Time- and $\mathrm{pH}$-dependent studies illustrated in this review have identified important factors for understanding the protein-directed synthesis of Au NCs. As a result of these new bio-nanomaterials, knowledge of protein-Au interactions has greatly improved from the recent progress made in this field.

However, only a few studies thus far have contributed investigations of Au NC local structure although many studies have been able to report various cluster sizes with mass spectrometry. Further investigation of the protein-nanocluster bonding environment remains to be explored. Even though protein-Au NCs show initial signs of good biocompatibility, it is expected that many more in vivo and in vitro experiments will be conducted before further integration into biomedical applications beyond the current research level. With protein-Au NCs still in their infancy, many rising applications, such as sensitive fluorescence detection and biolabeling, appear to be possible in the upcoming years.

\section{Acknowledgments}

The authors would like to thank the Natural Sciences and Engineering Research Council (NSERC) of Canada for financial support in the form of Discovery Grants.

\section{References}

1. M. Zhu et al., "Correlating the crystal structure of a thiol-protected $\mathrm{Au}_{25}$ cluster and optical properties," J. Am. Chem. Soc. 130(18), 5883-5885 (2008), http://dx.doi.org/10.1021/ ja801173r. 
2. J. Zheng, P. R. Nicovich, and R. M. Dickson, "Highly fluorescent noble metal quantum dots," Ann. Rev. Phys. Chem. 58(1), 409-431 (2007), http://dx.doi.org/10.1146/annurev .physchem.58.032806.104546.

3. J. Zheng, C. Zhang, and R. M. Dickson, "Highly fluorescent, water-soluble, size-tunable gold quantum dots," Phys. Rev. Lett. 93(7), 077402 (2004), http://dx.doi.org/10.1103/ PhysRevLett.93.077402.

4. J. P. Wilcoxon et al., "Photoluminescence from nanosize gold clusters," J. Chem. Phys. 108(21), 9137-9143 (1998), http://dx.doi.org/10.1063/1.476360.

5. J. Zheng, J. T. Petty, and R. M. Dickson, "High quantum yield blue emission from watersoluble $\mathrm{Au}_{8}$ nanodots," J. Am. Chem. Soc. 125(26), 7780-7781 (2003), http://dx.doi.org/10 $.1021 / \mathrm{ja} 035473 \mathrm{v}$.

6. G. Wang et al., "Near-IR luminescence of monolayer-protected metal clusters," J. Am. Chem. Soc. 127(3), 812-813 (2005), http://dx.doi.org/10.1021/ja0452471.

7. T. P. Bigioni, R. L. Whetten, and Ö. Dag, "Near-infrared luminescence from small gold nanocrystals," J. Phys. Chem. B 104(30), 6983-6986 (2000), http://dx.doi.org/10.1021/ jp993867w.

8. Y. Bao et al., "Nanoparticle-free synthesis of fluorescent gold nanoclusters at physiological temperature," J. Phys. Chem. C 111(33), 12194-12198 (2007), http://dx.doi.org/10.1021/ jp071727d.

9. D. Lee et al., "Electrochemistry and optical absorbance and luminescence of molecule-like $\mathrm{Au}_{38}$ nanoparticles," J. Am. Chem. Soc. 126(19), 6193-6199 (2004), http://dx.doi.org/10 $.1021 / \mathrm{ja} 049605 \mathrm{~b}$.

10. J. Shan and H. Tenhu, "Recent advances in polymer protected gold nanoparticles: synthesis, properties and applications," Chem. Commun. (44), 4580-4598 (2007), http://dx.doi.org/10 $.1039 / \mathrm{B} 707740 \mathrm{H}$.

11. M. Grzelczak et al., "Shape control in gold nanoparticle synthesis," Chem. Soc. Rev. 37(9), 1783-1791 (2008), http://dx.doi.org/10.1039/b711490g.

12. R. Sardar et al., "Gold nanoparticles: past, present, and future," Langmuir 25(24), 13840-13851 (2009), http://dx.doi.org/10.1021/la9019475.

13. R. Jin, "Quantum sized, thiolate-protected gold nanoclusters," Nanoscale 2(3), 343-362 (2010), http://dx.doi.org/10.1039/b9nr00160c.

14. J. Akola et al., "On the structure of thiolate-protected $\mathrm{Au}_{25}$," J. Am. Chem. Soc. 130(12), 3756-3757 (2008), http://dx.doi.org/10.1021/ja800594p.

15. J. F. Parker, C. A. Fields-Zinna, and R. W. Murray, "The story of a monodisperse gold nanoparticle: $\mathrm{Au}_{25} L_{18}$," Accounts. Chem. Res. 43(9), 1289-1296 (2010), http://dx.doi .org/10.1021/ar100048c.

16. M. Zhu et al., "Conversion of anionic $\left[\mathrm{Au}_{25}\left(\mathrm{SCH}_{2} \mathrm{CH}_{2} \mathrm{Ph}\right)_{18}\right]^{-}$cluster to charge neutral cluster via air oxidation," J. Phys. Chem. C 112(37), 14221-14224 (2008), http://dx.doi .org/10.1021/jp805786p.

17. P. D. Jadzinsky et al., "Structure of a thiol monolayer-protected gold nanoparticle at 1.1 Å resolution," Science 318(5849), 430-433 (2007), http://dx.doi.org/10.1126/science .1148624 .

18. A. A. Herzing et al., "Identification of active gold nanoclusters on iron oxide supports for CO oxidation," Science 321(5894), 1331-1335 (2008), http://dx.doi.org/10.1126/science .1159639.

19. M. Turner et al., "Selective oxidation with dioxygen by gold nanoparticle catalysts derived from 55-atom clusters," Nature 454(7207), 981-984 (2008), http://dx.doi.org/10.1038/ nature07194.

20. Y. Zhu, H. Qian, and R. Jin, "Catalysis opportunities of atomically precise gold nanoclusters," J. Mater. Chem. 21(19), 6793-6799 (2011), http://dx.doi.org/10.1039/c1jm10082c.

21. D.-en Jiang et al., "The smallest thiolated gold superatom complexes," J. Phys. Chem. C 113(40), 17291-17295 (2009), http://dx.doi.org/10.1021/jp9035937.

22. G. A. Simms, J. D. Padmos, and P. Zhang, "Structural and electronic properties of protein/ thiolate-protected gold nanocluster with 'staple' motif: A XAS, L-DOS, and XPS study," J. Chem. Phys. 131(21), 214703 (2009), http://dx.doi.org/10.1063/1.3268782. 
Chevrier, Chatt, and Zhang: Properties and applications of protein-stabilized fluorescent gold...

23. A. Dass, "Mass spectrometric identification of $\mathrm{Au}_{68}(\mathrm{SR})_{34}$ molecular gold nanoclusters with 34-electron shell closing," J. Am. Chem. Soc. 131(33), 11666-11667 (2009), http://dx.doi.org/10.1021/ja904713f.

24. M. A. MacDonald et al., "The structure and bonding of $\mathrm{Au}_{25}(\mathrm{SR})_{18}$ nanoclusters from EXAFS: the interplay of metallic and molecular behavior," J. Phys. Chem. C 115(31), 15282-15287 (2011), http://dx.doi.org/10.1021/jp204922m.

25. Z. Wu and R. Jin, "On the ligand's role in the fluorescence of gold nanoclusters," Nano Lett. 10(7), 2568-2573 (2010), http://dx.doi.org/10.1021/nl101225f.

26. E. S. Shibu et al., "Ligand exchange of $\mathrm{Au}_{25} \mathrm{SG}_{18}$ leading to functionalized gold clusters: spectroscopy, kinetics, and luminescence," J. Phys. Chem. 112(32), 12168-12176 (2008), http://dx.doi.org/10.1021/jp8045033.

27. L. Shang, S. Dong, and G. U. Nienhaus, "Ultra-small fluorescent metal nanoclusters: synthesis and biological applications," Nano Today 6(4), 401-418 (2011), http://dx.doi.org/10 .1016/j.nantod.2011.06.004.

28. E. Katz and I. Willner, "Integrated nanoparticle-biomolecule hybrid systems: synthesis, properties, and applications," Angew. Chem. Int. Ed. 43(45), 6042-6108 (2004), http:// dx.doi.org/10.1002/(ISSN)1521-3773.

29. M. B. Dickerson, K. H. Sandhage, and R. R. Naik, "Protein- and peptide-directed syntheses of inorganic materials," Chem. Rev. 108(11), 4935-4978 (2008), http://dx.doi.org/10.1021/ cr8002328.

30. X. Gao et al., "In vivo cancer targeting and imaging with semiconductor quantum dots," Nat. Biotechnol. 22(8), 969-976 (2004), http://dx.doi.org/10.1038/nbt994.

31. Y.-W. Lin, C.-C. Huang, and H.-T. Chang, "Gold nanoparticle probes for the detection of mercury, lead and copper ions," Analyst 136(5), 863-871 (2011), http://dx.doi.org/10.1039/ c0an00652a.

32. F. Wang et al., "Luminescent nanomaterials for biological labelling," Nanotechnology 17(1), R1-R13 (2006), http://dx.doi.org/10.1088/0957-4484/17/1/R01.

33. N. Goswami, R. Saha, and S. K. Pal, "Protein-assisted synthesis route of metal nanoparticles: exploration of key chemistry of the biomolecule," J. Nanopart. Res. 13(10), 5485-5495 (2011), http://dx.doi.org/10.1007/s11051-011-0536-3.

34. H. Wei et al., "Time-dependent, protein-directed growth of gold nanoparticles within a single crystal of lysozyme," Nat. Nanotechnol. 6(2), 93-97 (2011), http://dx.doi.org/10.1038/ nnano.2010.280.

35. K. Chaudhari, P. L. Xavier, and T. Pradeep, "Understanding the evolution of luminescent gold quantum clusters in protein templates," ACS Nano. 5(11), 8816-8827 (2011), http://dx .doi.org/10.1021/nn202901a.

36. F. Bensebaa et al., "XPS study of metal-sulfur bonds in metal-alkanethiolate materials," Surface Sci. 405(1), L472-L476 (1998), http://dx.doi.org/10.1016/S0039-6028(98) 00097-1.

37. K. M. Harkness, D. E. Cliffel, and J. A. McLean, "Characterization of thiolate-protected gold nanoparticles by mass spectrometry," Analyst 135(5), 868-874 (2010), http://dx.doi .org/10.1039/b922291j.

38. Y.-T. Tao et al., "Structure evolution of aromatic-derivatized thiol monolayers on evaporated gold," Langmuir 13(15), 4018-4023 (1997), http://dx.doi.org/10.1021/la9700984.

39. T. Yang et al., "Synthesis, characterization, and self-assembly of protein lysozyme monolayer-stabilized gold nanoparticles," Langmuir 23(21), 10533-10538 (2007), http:// dx.doi.org/10.1021/la701649z.

40. J. L. Burt et al., "Noble-metal nanoparticles directly conjugated to globular proteins," Langmuir 20(26), 11778-11783 (2004), http://dx.doi.org/10.1021/la048287r.

41. A. G. Tkachenko et al., "Multifunctional gold nanoparticle-peptide complexes for nuclear targeting," J. Am. Chem. Soc. 125(16), 4700-4701 (2003), http://dx.doi.org/10.1021/ ja0296935.

42. L. Shang et al., "pH-dependent protein conformational changes in albumin: gold nanoparticle bioconjugates: a spectroscopic study," Langmuir 23(5), 2714-2721 (2007), http://dx.doi.org/10.1021/la062064e. 
43. N. Wangoo, C. R. Suri, and G. Shekhawat, "Interaction of gold nanoparticles with protein: a spectroscopic study to monitor protein conformational changes," Appl. Phys. Lett. 92(13), 133104 (2008), http://dx.doi.org/10.1063/1.2902302.

44. J. H. Fendler, "Biomineralization inspired preparation of nanoparticles and nanoparticulate films," Curr. Opin. Solid. St. M. 2(3), 365-369 (1997), http://dx.doi.org/10.1016/S13590286(97)80129-5.

45. D. Bhattacharya and R. K. Gupta, "Nanotechnology and potential of microorganisms," Crit. Rev. Biotechnol. 25(4), 199-204 (2005), http://dx.doi.org/10.1080/07388550500361994.

46. W. J. Crookes-Goodson, J. M. Slocik, and R. R. Naik, "Bio-directed synthesis and assembly of nanomaterials," Chem. Soc. Rev. 37(11), 2403-2412 (2008), http://dx.doi.org/10.1039/ b702825n.

47. C.-L. Chen and N. L. Rosi, "Peptide-based methods for the preparation of nanostructured inorganic materials," Angew. Chem. Int. Ed. 49(11), 1924-1942 (2010), http://dx.doi.org/10 $.1002 /$ anie.200903572.

48. M. A. Albrecht, C. W. Evans, and C. L. Raston, "Green chemistry and the health implications of nanoparticles," Green Chem. 8(5), 417-432 (2006), http://dx.doi.org/10.1039/ b517131h.

49. J. Xie, Y. Zheng, and J. Y. Ying, "Protein-directed synthesis of highly fluorescent gold nanoclusters," J. Am. Chem. Soc. 131(3), 888-889 (2009), http://dx.doi.org/10.1021/ ja806804u.

50. D. Hu et al., "Highly selective fluorescent sensors for $\mathrm{Hg}^{2+}$ based on bovine serum albumincapped gold nanoclusters," Analyst 135(6), 1411-1416 (2010), http://dx.doi.org/10.1039/ c000589d.

51. A. Retnakumari et al., "Molecular-receptor-specific, non-toxic, near-infrared-emitting Au cluster-protein nanoconjugates for targeted cancer imaging," Nanotechnology 21(5), 055103 (2010), http://dx.doi.org/10.1088/0957-4484/21/5/055103.

52. M. A. H. Muhammed et al., "Luminescent quantum clusters of gold in bulk by albumininduced core etching of nanoparticles: metal ion sensing, metal-enhanced luminescence, and biolabeling," Chem. Eur. J. 16(33), 10103-10112 (2010), http://dx.doi.org/10.1002/ chem.201000841.

53. X. Wang et al., "Ultrasensitive fluorescence detection of glutaraldehyde in water samples with bovine serum albumin-Au nanoclusters," Microchem. J. 99(2), 327-331 (2011), http:// dx.doi.org/10.1016/j.microc.2011.06.004.

54. X. Le Guével et al., "Formation of fluorescent metal ( $\mathrm{Au}, \mathrm{Ag})$ nanoclusters capped in bovine serum albumin followed by fluorescence and spectroscopy," J. Phys. Chem. C 115(22), 10955-10963 (2011), http://dx.doi.org/10.1021/jp111820b.

55. H. Wei et al., "Lysozyme-stabilized gold fluorescent cluster: synthesis and application as $\mathrm{Hg}^{2+}$ sensor," Analyst 135(6), 1406-1410 (2010), http://dx.doi.org/10.1039/c0an00046a.

56. C. Shao et al., "Eggshell membrane as a multimodal solid state platform for generating fluorescent metal nanoclusters," J. Mater. Chem. 21(9), 2863-2866 (2011), http://dx.doi .org/10.1039/c0jm04071a.

57. X. L. Guével, N. Daum, and M. Schneider, "Synthesis and characterization of human transferrin-stabilized gold nanoclusters," Nanotechnology 22(27), 275103 (2011), http:// dx.doi.org/10.1088/0957-4484/22/27/275103.

58. P. L. Xavier et al., "Luminescent quantum clusters of gold in transferrin family protein, lactoferrin exhibiting FRET," Nanoscale 2(12), 2769-2776 (2010), http://dx.doi.org/10 $.1039 / \mathrm{c} 0 \mathrm{nr} 00377 \mathrm{~h}$.

59. H. Kawasaki et al., "Trypsin-stabilized fluorescent gold nanocluster for sensitive and selective $\mathrm{Hg}^{2+}$ detection," Anal. Sci. 27(6), 591-596 (2011), http://dx.doi.org/10.2116/analsci.27 .591 .

60. H. Kawasaki et al., "pH-dependent synthesis of pepsin-mediated gold nanoclusters with blue green and red fluorescent emission," Adv. Funct. Mater 21(18), 3508-3515 (2011), http://dx.doi.org/10.1002/adfm.201100886.

61. C.-L. Liu et al., "Insulin-directed synthesis of fluorescent gold nanoclusters: preservation of insulin bioactivity and versatility in cell imaging." Angew. Chem. Int. Ed. 50(31), 7056-7060 (2011), http://dx.doi.org/10.1002/anie.v50.31. 
Chevrier, Chatt, and Zhang: Properties and applications of protein-stabilized fluorescent gold...

62. F. Wen et al., "Horseradish peroxidase functionalized fluorescent gold nanoclusters for hydrogen peroxide sensing," Anal. Chem. 83(4), 1193-1196 (2011), http://dx.doi.org/10 $.1021 / \mathrm{ac} 1031447$.

63. Z. Zhong et al., "The surface chemistry of Au colloids and their interactions with functional amino acids," J. Phys. Chem. B 108(13), 4046-4052 (2004), http://dx.doi.org/10.1021/ jp037056a.

64. R. L. Willett et al., "Differential adhesion of amino acids to inorganic surfaces," PNAS 102(22), 7817-7822 (2005), http://dx.doi.org/10.1073/pnas.0408565102.

65. R. R. Naik et al., "Peptide templates for nanoparticle synthesis derived from polymerase chain reaction-driven phage display," Adv. Funct. Mater. 14(1), 25-30 (2004), http://dx.doi .org/10.1002/(ISSN)1616-3028.

66. S. Brown, M. Sarikaya, and E. Johnson, "A genetic analysis of crystal growth," J. Mol. Biol. 299(3), 725-735 (2000), http://dx.doi.org/10.1006/jmbi.2000.3682.

67. Y. N. Tan, J. Y. Lee, and D. I. C. Wang, "Uncovering the design rules for peptide synthesis of metal nanoparticles," J. Am. Chem. Soc. 132(16), 5677-5686 (2010), http://dx.doi.org/10 $.1021 / \mathrm{ja} 907454 \mathrm{f}$.

68. N. K. Chaki et al., "Ubiquitous 8 and $29 \mathrm{kDa}$ gold: alkanethiolate cluster compounds: massspectrometric determination of molecular formulas and structural implications," $J$. Am. Chem. Soc. 130(27), 8608-8610 (2008), http://dx.doi.org/10.1021/ja8005379.

69. J. W. Hudgens et al., "Reaction mechanism governing formation of 1,3-bis(diphenylphosphino)propane-protected gold nanoclusters," Inorg. Chem. 50(20), 10178-10189 (2011), http://dx.doi.org/10.1021/ic2018506.

70. Y. Negishi, K. Nobusada, and T. Tsukuda, "Glutathione-protected gold clusters revisited: bridging the gap between gold(I)-thiolate complexes and thiolate-protected gold nanocrystals," J. Am. Chem. Soc. 127(14), 5261-5270 (2005), http://dx.doi.org/10.1021/ja042218h.

71. C. Sun et al., "Controlling assembly of paired gold clusters within apoferritin nanoreactor for in vivo kidney targeting and biomedical imaging," J. Am. Chem. Soc. 133(22), 8617-8624 (2011), http://dx.doi.org/10.1021/ja200746p.

72. A. M. P. Hussain et al., "Au-nanocluster emission based glucose sensing," Biosens. Bioelectron. 29(1), 60-65 (2011), http://dx.doi.org/10.1016/j.bios.2011.07.066.

73. I. Sakanaga et al., "Photoluminescence from excited energy bands in $\mathrm{Au}_{25}$ Nanoclusters," Appl. Phys. Express 4(9), 095001 (2011), http://dx.doi.org/10.1143/APEX.4.095001.

74. S. He et al., "Design of a gold nanoprobe for rapid and portable mercury detection with the naked eye," Chem. Commun. (40), 4885-4887 (2008), http://dx.doi.org/10.1039/ B811528A.

75. C.-C. Huang and H.-T. Chang, "Parameters for selective colorimetric sensing of mercury(II) in aqueous solutions using mercaptopropionic acid-modified gold nanoparticles," Chem. Commun. (12), 1215-1217 (2007), http://dx.doi.org/10.1039/B615383F.

76. J.-S. Lee, M. S. Han, and C. A. Mirkin, "Colorimetric detection of mercuric ion $\left(\mathrm{Hg}^{2+}\right)$ in aqueous media using DNA-functionalized gold nanoparticles," Angew. Chem. Int. Ed. 46(22), 4093-4096 (2007), http://dx.doi.org/10.1002/(ISSN)1521-3773.

77. D. $\mathrm{Li}, \mathrm{A}$. Wieckowska, and I. Willner, "Optical analysis of $\mathrm{Hg}^{2+}$ ions by oligonucleotidegold-nanoparticle hybrids and DNA-based machines," Angew. Chem. Int. Ed. 47(21), 3927-3931 (2008), http://dx.doi.org/10.1002/anie.v47:21.

78. C.-W. Liu et al., "Detection of mercury(II) based on $\mathrm{Hg}^{2+}$-DNA complexes inducing the aggregation of gold nanoparticles," Chem. Commun. (19), 2242-2244 (2008), http://dx.doi .org/10.1039/B719856F.

79. Y. Kim, R. C. Johnson, and J. T. Hupp, "Gold nanoparticle-based sensing of "spectroscopically silent" heavy metal ions," Nano. Lett. 1(4), 165-167 (2001), http://dx.doi.org/ 10.1021/n10100116.

80. J. Xie, Y. Zheng, and J. Y. Ying, "Highly selective and ultrasensitive detection of $\mathrm{Hg}^{2+}$ based on fluorescence quenching of Au nanoclusters by $\mathrm{Hg}^{2+}-\mathrm{Au}^{+}$interactions," Chem. Commun. (46), 961-963 (2010), http://dx.doi.org/10.1039/B920748A.

81. Y. Liu et al., "Gold-nanocluster-based fluorescent sensors for highly sensitive and selective detection of cyanide in water," Adv. Funct. Mater. 20(6), 951-956 (2010), http://dx.doi.org/ 10.1002/adfm.200902062. 
82. M. S. Bakshi et al., "Biomineralization of gold nanoparticles by lysozyme and cytochrome C and their applications in protein film formation," Langmuir 26(16), 13535-13544 (2010), http://dx.doi.org/10.1021/la101701f.

83. M. Guli et al., "Template-directed synthesis of nanoplasmonic arrays by intracrystalline metalization of cross-linked lysozyme crystals," Angew. Chem. Int. Ed. 49(3), 520-523 (2010), http://dx.doi.org/10.1002/anie.200905070.

84. X. Tu, W. Chen, and X. Guo, "Facile one-pot synthesis of near-infrared luminescent gold nanoparticles for sensing copper (II)," Nanotechnology 22(9), 095701 (2011), http://dx.doi .org/10.1088/0957-4484/22/9/095701.

85. R. Bardhan et al., "Fluorescence enhancement by Au nanostructures: nanoshells and nanorods," ACS Nano 3(3), 744-752 (2009), http://dx.doi.org/10.1021/nn900001q.

86. H. Duan and S. Nie, "Etching colloidal gold nanocrystals with hyperbranched and multivalent polymers: a new route to fluorescent and water-soluble atomic clusters," J. Am. Chem. Soc. 129(9), 2412-2413 (2007), http://dx.doi.org/10.1021/ja067727t.

87. R. Zhou et al., "Atomically monodispersed and fluorescent sub-nanometer gold clusters created by biomolecule-assisted etching of nanometer-sized gold particles and rods," Chem. Eur. J. 15(19), 4944-4951 (2009), http://dx.doi.org/10.1002/chem.v15:19.

88. X. Yang et al., "Blending of $\mathrm{HAuCI}_{4}$ and histidine in aqueous solution: a simple approach to the $\mathrm{Au}_{10}$ cluster," Nanoscale 3(6), 2596-2601 (2011), http://dx.doi.org/10.1039/ c1nr10287g.

89. C.-A. J. Lin et al., "Synthesis, characterization, and bioconjugation of fluorescent gold nanoclusters toward biological labeling applications," ACS Nano., 3(2), 395-401 (2009).

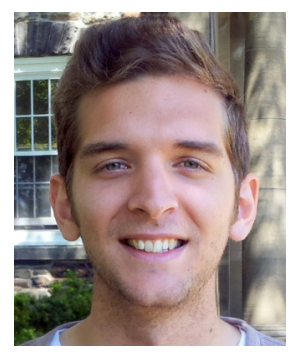

Daniel M. Chevrier is currently a graduate student in the chemistry department at Dalhousie University. He completed a BSc Honours in chemistry at Dalhousie University. While in his undergraduate program, he began his work with Peng Zhang studying iron oxide nanoparticles for their use as drug delivery systems. In 2011, he started his graduate work at Dalhousie University with Peng Zhang and co-supervisor Amares Chatt directing his research towards studying the properties and local structure of fluorescent protein-gold nanoclusters.

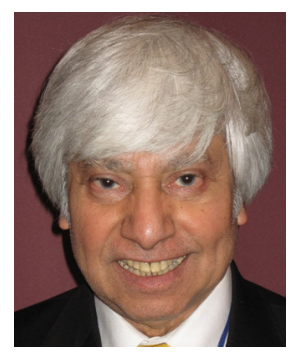

Amares Chatt received his BSc (1964, University of Calcutta, India), MSc (1967, University of Roorkee, India), MSc (1970, University of Waterloo, Canada) and PhD (1974, University of Toronto). He has been a full professor (1985 to 2008), Killam Professor of Chemistry (2001 to 2006), director of the SLOWPOKE-2 reactor facility (1987 to 2011), and is currently an adjunct professor of the Department of Chemistry, Dalhousie University in Halifax, Nova Scotia, Canada. His research interests include studies on $\mathrm{x}$-ray spectroscopy of nanomaterials and gamma-ray spectroscopy of radionuclides.

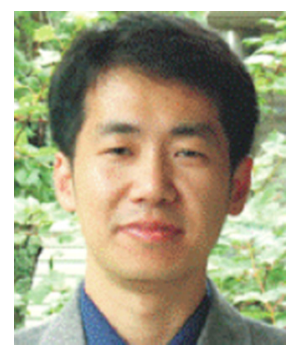

Peng Zhang received his BSc (1993) and MSc (1997) from Jilin University, and $\mathrm{PhD}$ (2003) from University of Western Ontario. He was an NSERC postdoctoral fellow at McGill University from 2003 to 2005. Currently, he is an associate professor in the Department of Chemistry, Dalhousie University in Halifax, Nova Scotia, Canada. His research focuses on the x-ray spectroscopy studies of nanomaterials and their applications in catalysis and biomedicine. 